\title{
Dynamics of Inclusion Policy on Quality of Higher Education in Selected Universities, in Kenya
}

\author{
Wekesa Moses Soita $^{1 *}$, Kisilu M. Kitainge ${ }^{2}$ \\ ${ }^{1} \mathrm{PhD}$-Candidate, School of Education, University of Eldoret, P.O Box 2500, Eldoret, Kenya \\ ${ }^{2}$ Professor, School of Education, University of Eldoret, P.O Box 2500, Eldoret, Kenya
}

\begin{abstract}
DOI: $10.36348 /$ jaep.2021.v05i01.003
| Received: 22.12.2020 | Accepted: 04.01.2021 | Published: 26.01.2021

*Corresponding author: Wekesa Moses Soita

\section{Abstract}

Universities have played a basic role in research, training and teaching professionals in different fields of knowledge. The importance of these Universities had been re-empowered, particularly with the development of globalization. Quality higher education in Kenya appears to be influenced by several factors which include but not restricted to policies on quality education; admissions, funding, policies on inclusion and constitutional requirements. The study objective was to establish the impact of inclusion policy on quality of higher education. The sample size of the study was 195 where top managers of the selected Universities were 103 while students were 92. The questionnaire was used on the Admissions Officers, Deans, DVCs, DQA, finance officers, HODs, Data was analyzed using both descriptive and inferential statistics. The study established that there was a positive and statistically significant relationship between inclusion policy and access to higher education. The study recommended that Inclusion Policy-Public Universities should strive to make Universities environment inclusive and since the Universities in existence are in trouble, no more Universities should be opened.
\end{abstract}

Keywords: Dynamics, Inclusion, Policy, Quality, Higher Education, Universities.

Copyright () 2021 The Author(s): This is an open-access article distributed under the terms of the Creative Commons Attribution 4.0 International License (CC BY-NC 4.0) which permits unrestricted use, distribution, and reproduction in any medium for non-commercial use provided the original author and source are credited.

\section{INTRODUCTION}

The Department of Education through its higher education department has the responsibility for defining national policies For a considerable length of time, England had a cradle body (HEFCE- Higher Education Funding Council for England), which was responsible for apportioning public assets to colleges and other tertiary institutions. HEFCE was nullified in 2017 and supplanted with the Office for Students, which is the new advanced education controller. Advanced education Policy Documents incorporate the important authority report (characterizing England's national advanced education methodology) is the Higher Education and Research Act 2017. The United Kingdom 2010 Equality Act sets the parameters for desires for equivalent treatment and equivalent open doors crosswise over divisions, UNESCO [1].

The inclusion policy in higher education are communicated by means of all advanced education suppliers who charge an expense above $£ 6000$ or who wish to be enlisted through the Office for Students giving what is called an Access and Participation Plan. In the UK, (2017), the Department of Education distributed a direction note for advanced education suppliers that spotlights on making a comprehensive learning and showing condition for students with inabilities: Inclusive education and learning in advanced education as a course to magnificence. Value target institutions recognized in the arrangement reports are; Low-pay students, Gender gatherings, Minority gatherings: in light of ethnicity, religion, and Students with inability. Secured statuses under the UK 2010 Equality Act are: age; handicap; sex reassignment; marriage and common organization; pregnancy and maternity; race; religion or conviction; sex; sexual direction. Britain intends to twofold the quantity of students entering $\mathrm{HE}$ from low investment territories from 2011 to 2020. Britain does not have an independent approach record committed to value advancement in advanced education. The fundamental monetary instrument to advance value is the pay unexpected student credit plan set up by the legislature. As a feature of Access and Participation Plans, HE suppliers are obliged to contribute an extent of their education cost pay on grants/bursaries and the sort of non-money related work. The principle non-financial instruments to advance value are: Outreach and extension projects, Academic and vocation direction and guiding, Flexible pathways and moves/Recognition 
Wekesa Moses Soita \& Kisilu M. Kitainge., J Adv Educ Philos, Jan, 2021; 5(1): 22-26

of earlier learning, Reformed confirmation methods/Affirmative activity projects, and Retention programs.

According to UNDP [2] The Quality Assurance Agency for Higher Education anticipates that advanced education establishments should: "work evenhanded, substantial and dependable procedures of evaluation, including for the acknowledgment of earlier realizing, which empower each student to show the degree to which they have accomplished the proposed learning results for the credit or capability being looked for." The UK Quality Code states in the majority of its various segments that the general code promotes and thinks about uniformity of chance and comprehensive learning in Higher Education organizations: "A comprehensive domain for learning foresees the differed necessities of students, for instance, on account of an announced inability, explicit social foundation, area or age, and expects to guarantee that all students have equivalent access to instructive chances. Advanced education suppliers, staff and students all have a job in and duty regarding advancing correspondence."

Winzer \& Mazure [3], note that acknowledgment of all students is the obligation of each educator, not all have the right stuff required for effective consideration nor are open to the standards and requests of incorporation. The movement to integrate students into the education mainstream according to Winzer \& Mazure [3] did not begin with the students who had disabilities. He noted for example, in 1779, Thomas Jefferson began the struggle to include students from poor families in the education system. Thomas proposed the first state supported educational plan in Virginia in an attempt to allow children other than those from wealthy families, an opportunity to receive education services. In Kenya, comprehensive training is a subsection of the general instruction, and is characterized as: Education which gives suitable adjustment in educational plan, showing techniques, instructive asset, and mode of correspondence or the learning condition so as to provide food for individual contrasts in learning [4].

\section{Statement of the Problem}

The number of higher education institutions in Kenya has also expanded from one institution, the University of Nairobi (UON) in 1970 to seventy one universities comprising thirty-five public universities and thirty-six private universities in 2017 [5]. Ludeman et al., [6] assert that higher education institutions in Kenya now need to focus on students and put their needs at the center of all that they do. Quality higher learning in Kenya appears to be influenced by several factors which include but not limited to policies on inclusion and constitutional requirements. These policies are said to affect admission to higher education in Kenya. However, the extent to which the identified policies impact on access to higher learning in Kenya have not been extensively studied. This study, therefore, set out to investigate the impact of Inclusion Policy on Quality of Higher Education in selected universities, in Kenya.

\section{Objective of the Study}

To establish the impact of Inclusion Policy on Quality of Higher Education in selected universities, in Kenya.

\section{Research Question}

What is the impact of Inclusion Policy on Quality of Higher Education in selected Universities, in Kenya?

\section{Research Hypothesis}

$\mathrm{H}_{0}$ : There is no statistically significant relationship between inclusion policy and quality of University education.

\section{Ethical Considerations}

The researcher promised confidentiality to the subjects (Admissions Officers, Deans, DVCs, DQA, finance officers, HODs, and librarians, and students). For those respondents who were not concerned with confidentiality, consent was sought before revealing any information. A respondent's name was not to be disclosed when the required information was sensitive for example details of finance records. An individual code was used in-case of a follow up activity

\section{RESEARCH METHODOLOGY AND METHODS}

Pragmatism paradigm was used in this study. This paradigm employs both qualitative and quantitative techniques. According to Dewey [7], advocates of mixed method research have proposed Pragmatism as a paradigm for social research emphasizing more on the practical part rather than on the philosophical one. Qualitative research was used because it allowed for rich details and interpretations of policies for example open ended questionnaires. The qualitative research aims to explore issues and gain indepth understanding of the policies. Here the type of data employed was that the phenomenon would be described by respondents in a narrative manner. The scope of inquiry was broad and thematic in nature. Quantitative Research method was also used here. This research method was used to confirm numeral events on access policies like number of students admitted, fees paid by students, number of lecturers per program, ratio of full time lecturers to part time lecturers, volumes of books in libraries, number of offices against officers, number of playgrounds against student enrolment, lecturer's contact hours with students, and student /lecturer ratio. This mixed method was applicable here because it would consider the feelings and insights of respondents and answer questions of how many. Also both qualitative and quantitative methods would 
Wekesa Moses Soita \& Kisilu M. Kitainge., J Adv Educ Philos, Jan, 2021; 5(1): 22-26

complement each other to maximize the strengths and minimize the limitations of each.

\section{FINDINGS AND DISCUSSION}

The objective of this study was to establish the impact of Inclusion Policy on Quality of Higher
Education in selected Universities, in Kenya. To achieve this objective, the respondents were asked to indicate if the facilities to support inclusive education were in place and if they were adequate. Their responses were as shown in Table-1.

Table-1: Facilities to Support Inclusive Education

\begin{tabular}{|l|l|l|l|l|}
\hline Facilities & $\mathbf{2 0 1 5 / 2 0 1 6}$ & $\mathbf{2 0 1 6} / \mathbf{2 0 1 7}$ & $\mathbf{2 0 1 7 / 2 0 1 8}$ & $\mathbf{2 0 1 8} / \mathbf{2 0 1 9}$ \\
\hline Toilet & None & 3 & 3 & 3 \\
\hline Ramps & Yes & Yes & Yes & Yes \\
\hline Windows & 0 & 1 & 1 & 1 \\
\hline Playground & Yes & Yes & Yes & Yes \\
\hline Brail & 0 & 0 & 1 & 1 \\
\hline Hearing-aids & None & None & None & None \\
\hline Wheel-chairs & None & None & None & None \\
\hline Lecturers for special need education & 1 & 1 & 3 & 4 \\
\hline Amplification devices & None & None & None & None \\
\hline Special lighting & None & None & None & None \\
\hline Preferential sitting & None & None & None & None \\
\hline Least restrictive environment & None & None & Yes & Yes \\
\hline
\end{tabular}

\section{Source: Research data 2019}

The analysis results in Table-1 shows The examination likewise proceeded to build up that the condition that these understudies that there were 9 toilets ( 3 in each University where the study was done), some buildings had ramps, there were three windows and only two brails available in the Universities where the study was done. Lecturers for special education were available but not enough and even some had little no required skills to handle the hand-capped learners. The study also noted some restricted environment which was not adequate for inclusive education in the Universities where the study was done. However, the study noted that there were no wheel-chairs, amplification devices, special lighting, and preferential sitting areas for students with special needs. This implied that the Universities were not implementing inclusion policy that could facilitate the access to higher education by the challenged members of the society. This agreed with a investigate on difficulties confronting execution of comprehensive training system done at the University of Nairobi [8], which uncovered that there was an intense lack of educating and learning assets to provide food for learning incapacity understudies in comprehensive settings. The discoveries likewise uncovered that the educators who were available in comprehensive study halls did not have the required preparing and capabilities to deal with understudies with learning inabilities were learning in needed essential necessities so as to make it helpful enough for figuring out how to happen. A non-inclusive environment in universities prevents students with disabilities from accessing University education even if they acquired minimum entry grade $(c+)$ in KCSE exam. This disagreed with the Ministry of Education [4], in the National report on improvement of instruction, which asserted that Kenya had grasped comprehensive training that given quality instruction to all youngsters, youth and grown-ups through focused help to explicit or powerless gatherings moving ceaselessly from the customary perspective on comprehensive training as a giving training for kids exceptional needs. Universities should advocate for inclusive environment for equitable access to quality education in higher learning institutions. CUE [9] recommends that each program shall be supported by appropriate and adequate number of facilities and equipment.

\section{Effect of Inclusion Policy on the Provision of Quality Education}

The respondents were asked to establish the effect of inclusion policy on the provision of quality education. Their responses were as shown in Table-1. 
Wekesa Moses Soita \& Kisilu M. Kitainge., J Adv Educ Philos, Jan, 2021; 5(1): $22-26$

Table-2: Effect of Inclusion Policy on the Provision of Quality Education

\begin{tabular}{|c|c|c|c|c|c|c|c|c|c|c|c|c|}
\hline \multirow{2}{*}{ Statement } & \multicolumn{2}{|c|}{ SD } & \multicolumn{2}{|l|}{$\mathrm{D}$} & \multicolumn{2}{|l|}{$\mathrm{U}$} & \multicolumn{2}{|l|}{$\mathrm{A}$} & \multicolumn{2}{|c|}{ SA } & \multicolumn{2}{|c|}{ TOTAL } \\
\hline & $\mathrm{F}$ & $\%$ & $\mathrm{~F}$ & $\%$ & $\mathrm{~F}$ & $\%$ & $\mathrm{~F}$ & $\%$ & $\mathrm{~F}$ & $\%$ & $\mathrm{~F}$ & $\%$ \\
\hline $\begin{array}{l}\text { With constant changes in human } \\
\text { resource market, many graduates } \\
\text { find their skills irrelevant to the } \\
\text { labor market }\end{array}$ & 0 & 0.0 & 26 & $\begin{array}{l}32.9 \\
1\end{array}$ & 0 & 0.0 & 26 & 32.91 & 27 & 34.17 & 79 & 100.0 \\
\hline $\begin{array}{l}\text { due to curriculum that is not } \\
\text { representative to modern-day } \\
\text { needs of labor market coupled } \\
\text { with tough structural adjustment } \\
\text { programs and recruitment } \\
\text { restrictions, many students are } \\
\text { unlucky to find employment. }\end{array}$ & 0 & 0.0 & 0 & 0.0 & 0 & 0.0 & 26 & 32.9 & 53 & 67.09 & 79 & 100.0 \\
\hline $\begin{array}{l}\text { Certain communities in Kenya } \\
\text { still maintain some cultural } \\
\text { practices that tend to disfavor } \\
\text { girls from getting access to } \\
\text { education }\end{array}$ & 0 & 0.0 & 0 & 0.0 & 26 & 32.9 & 53 & 67.09 & 0 & 0.0 & 79 & 100.0 \\
\hline $\begin{array}{l}\text { university programs meet quality } \\
\text { standards required by students, } \\
\text { lecturers and labor markets }\end{array}$ & 0 & 0.0 & 0 & 0.0 & 0 & 0.0 & 79 & 100 & 0 & 0.0 & 79 & 100.0 \\
\hline $\begin{array}{l}\text { Universities promote a quality } \\
\text { assurance culture in their } \\
\text { departments and involve all } \\
\text { stakeholders in achieving their } \\
\text { goals. }\end{array}$ & 0 & 0.0 & 0 & 0.0 & 26 & 32.9 & 53 & 67.09 & 0 & 0.0 & 79 & 100.0 \\
\hline $\begin{array}{l}\text { Students with disabilities are } \\
\text { provided with supplementary } \\
\text { aids and services to participate in } \\
\text { irregular education classes. }\end{array}$ & 0 & 0.0 & 26 & 32.9 & 26 & 32.9 & 27 & 34.17 & 0 & 0.0 & 79 & 100.0 \\
\hline $\begin{array}{l}\text { There is equal access to high } \\
\text { quality education in Kenya }\end{array}$ & 0 & 0.0 & 26 & 32.9 & 0 & 0.0 & 53 & 67.09 & 0 & 0.0 & 79 & 100.0 \\
\hline
\end{tabular}

Key: SA-strongly agree, A-agree, U-undecided, D-disagree, SD- strongly disagree Source: Research data 2019

Table-2 show that $32.9 \%$ of the respondents in each category; disagreed, and agreed that with constant change in human resource market, many graduates found their skills irrelevant to the labor market. However, there is a general agreement $(65.8 \%)$ that with constant change in human resource market, many graduates found their skills irrelevant to the labor market. This implied that there was need for reshuffling of the curriculum so as to be relevant to the labor market.

The results in Table 4.6.2 above revealed that $26(32.9 \%$ ), (mean 4.00 ) of the respondents agreed, $53(67.1 \%)$ of the respondents (mean 5.00) strongly agreed that due to curriculum that was not representative to modern-day needs of labor market coupled with tough structural adjustment programs and recruitment restrictions, many students were unlucky to find employment. Cumulatively,79 (100\%) of the respondents were of the idea that due to curriculum that was not representative to modern day needs of labor market coupled with tough structural adjustment programs and recruitment restrictions, many graduates did not get employment. This left the quality of these graduates questionable.

Table- 2 above also noted that $53(67.1 \%)$ of the respondents agreed and $26(32.9 \%)$ of the respondents were undecided that certain societies still maintain some cultural practices that tend to disfavor girls from getting access to education, $79(100 \%)$ of the respondents agreed that University programs met quality standards required by students, lecturers and labor markets, this was in terms of syllabus completion, duration of students spent in college, among others. $26(32.9 \%)$ of the respondents were undecided and $53(67.1 \%)$ of the respondents agreed that universities promoted a quality assurance culture in their departments and involved all stakeholders in achieving their goals, $32.9 \%$ of each category disagreed, undecided and agreed that students with disabilities were provided with supplementary aids and services to participate in irregular education classes and lastly but not least, $26(32.9 \%)$ of the respondents were undecided and $53(67.1 \%)$ of the respondents agreed that there was equal access to high quality education in Kenya. This is contrary to CUE's recommendation [9] that all each 
programme in the university shall be supported by an appropriate and adequate number of facilities and equipment.

As defined by UNESCO [1], Inclusive education is a persistent procedure of tending to and reacting to the decent variety of requirements everything being equal-paying little heed to components, for example, handicap, sex, age, ethnicity, language, HIV status, land area and sexuality perceiving that all individuals can learn. It frequently includes attempting to change the structures, frameworks, arrangements, practices and societies in schools and different foundations in charge of training, with the goal that they can react to the decent variety of understudies in their area. Incorporation underscores open doors for equivalent support, yet with choices for extraordinary help and offices as required, and for separation, inside a typical learning system.

\section{Testing Research Hypothesis}

Further, statistical analysis was done to establish whether there was a statistically significant relationship between inclusion policy and quality of higher education as per the hypothesis of the study.

Table-3: Correlation between inclusion policy and quality high education

\begin{tabular}{|r|l|l|}
\hline \multicolumn{2}{|c|}{} & Quality University Education in Kenya \\
\hline Inclusion Policy & Pearson Correlation & $.870^{*}$ \\
\cline { 2 - 3 } & Sig. (2-tailed) & .011 \\
\cline { 2 - 3 } & $\mathrm{N}$ & 76 \\
\hline & $*$. Correlation is significant at the 0.05 level (2-tailed). \\
$* *$. Correlation is significant at the 0.01 level (2-tailed).
\end{tabular}

The analysis results in Table-3 shows that there was a positive and statistically significant relationship between inclusion policy and quality of higher education at $\mathrm{r}=.870 * \mathrm{P}<.01$ significant level. This meant that we reject the null hypothesis which states that, "There is no statistically significant relationship between Inclusion Policy and quality of higher education" and accept the alternative one. The coefficient of determinant $\mathrm{R}^{2}$ established that inclusion policy contributes $75.7 \%$ variability to quality of higher education when other factors are held constant.

\section{CONCLUSIONS}

The study noted that Lecturers for special education were available but not enough and even some had little no required skills to handle the hand-capped learners. The study also noted some restricted environment which was not adequate for inclusive education in the Universities where the study was done. However, the study noted that there were no wheelchairs, amplification devices, special lighting, and preferential sitting areas for students with special needs. This implied that the campuses were not implementing inclusion policy that could facilitate the access to higher education by the challenged members of the society. The study concludes that there was a positive and statistically significant relationship between inclusion policy and quality of higher education.

\section{POLICY RECOMMENDATION}

Public Universities should strive to make Universities environment inclusive. Inclusion in education is rooted deeply in the democratic principles of justice and equal opportunity. Inclusive higher education is vital to the ongoing development of a democratic society. At the heart of inclusive education is the cultivation of a mindset that supports growth and respects human differences.

\section{REFERENCES}

1. UNESCO. (2005). Towards Knowledge Societies, Paris: UNESCO World Report.

2. UNDP. (2002). Constructing Knowledge Societies: New Challenges for Tertiary Education Washington, DC: World Bank.

3. Winzer, M., \& Mazure, K. (2000). Special education in the $21^{\text {st }}$ century: Issues of inclusion and reform. Gallaudet University Press, Washington, D.C.

4. Ministry of Education, Science and Technology. (2008). Mandate. Retrieved from http://www.scienceandtechnology.go.ke/

5. CUE. (2017). Quality Audit of Universities in Kenya. Nairobi: Commission of University Education.

6. Ludeman, R. B., Osfield, K. J., Hidalgo, E. I., Oste, D., \& Wang, H. S. (2009). 'Preface'. Students affairs and service in higher education: Global foundations, issues and best practices, (pp. ii-vi), Unesco and World Conference on Higher Education.

7. Dewey, J. (1925a/2008). Experience and Nature.

8. Ministry of Education and Ministry of Higher Education, Science Technology Sessional Paper No. 10. (2012): Policy Framework for Education and Training.

9. CUE. (2015). State of University Education in Kenya. Nairobi: Government Printers. 